\title{
RESEARCH AND THE PHYSIOTHERAPY PROFESSION IN SOUTH AFRICA - REFLECTIONS ON A Pilot StUdy
}

\begin{abstract}
The purpose of this paper is to present a perspective on Physiotherapy Research in South Africa, reflecting on results from a pilot study. Articles published in the South African Journal of Physiotherapy during the year 2002 constituted the sample for analysis. Of the 25 articles published, 17 were by South African Physiotherapists, with 11 coming from academics. Sixteen of the 25 articles (60\%) were 'research articles' - suggesting a satis-

MOTHABEN G DJ,
DTI, M PhyST - Pretoria ${ }^{1}$.
${ }^{1}$ Lecturer - Physiotherapy Deparment,
Faculty of Health Sciences, University of Pretoria.
factory level of research in the profession. However, the type and quality of research is questionable in terms of relevance and addressing the needs of our country. Professional issues emanating from the findings and their implications for physiotherapy are discussed. Major conclusions cannot be drawn from this pilot study due to the small sample and nature of the study. The paper also presents a proposed framework for a national strategy for physiotherapy research in South Africa, which will be verified through the main study and adapted accordingly.
\end{abstract}

KEY WORDS: PHYSIOTHERAPY RESEARCH, EVIDENCE BASED PRACTICE, OUTCOME RESEARCH.

\section{INTRODUCTION}

South Africa has undergone a vast number of changes in the past few years. In less than a decade, new health and education bills were passed, with the intention of ensuring equity and to meet the health needs of the country. The changes introduced to the South African national health system pose great challenges to educators in physiotherapy and other health professions. These challenges include the prevalence of very specific health disorders, limited resources, increased globalization through information technology and the pressure of evidence-based practice.

The physiotherapy profession has a historical tradition of practical and experience based knowledge. Although there has been an increase in research based knowledge in the past few decades, the challenges facing the profession are such that new ways of promoting research and further developing research within the profession are imperative (Dahlgren 1999). Practicing physiotherapists need to see research as an integral part of their professional practice and not just something for academics (Hurly 2000). Evidence based practice, which is defined as 'using the best available scientific evidence to guide practice' (Gulham 2000), is crucial for the survival and image of the profession. Our credi- bility as a profession is at risk if we are unable to demonstrate that our treatment approaches have a significant beneficial effect to our patients and are cost effective.

Physiotherapy research should primarily be aimed at promoting the health and well being of patients and should also examine the value of physiotherapy and physiotherapy services. Physiotherapy research efforts must endeavor to address issues pertinent to the South African community. We risk being labeled an irrelevant profession if we are not going to address priority health issues of the country. The National Health Bill (2001) states that health research must be directed at promoting health, preventing disease and disability and curing disease. The extent to which our physiotherapy research addresses these requirements remains a question.

'We will only know that we have reached our goals when research confirms the positive outcomes of our interventions. In the changing healthcare scenario in South Africa, we will have to prove that we can deliver a service to all who need it, and that the service truly makes a difference (Eales 2000)'.

The author is currently working on major research project investigating the status of physiotherapy research in South Africa. This paper reports on findings from a pilot study designed to establish whether the methodology of content analysis would be appropriate for the first phase of the main project. The first phase aims to conduct an analytical survey of the nature and content of publications in the South African Journal of Physiotherapy (SAJ Physiother).

This paper reflects on the pilot study results to elucidate the need for and the importance of research to our profession and to propose strategies for the South African Physiotherapists. Two main questions are addressed: Do the articles in the journal display relevance towards evidence-based practice and towards the country's health issues?

\section{METHODOLOGY}

\section{Sample}

Articles published in the SAJ Physiother during the year 2002 constituted the pilot sample for analysis.

\section{CORRESPONDENCE TO:}

Mrs. DJ Mothabeng

Physiotherapy Department, Faculty of Health Sciences, University of Pretoria

Tel: (012) 354-1200

Fax: (012) 354-1226

E-mail: mothadj@med.up.ac.za 


\section{Design}

An analytical survey using documentary research was used. Documentary research refers to the analysis of written documents using content analysis - a technique for describing and analysing written and other communication.

The author conducted the content analysis of the articles according to the method described in Currier (1990). The articles were read through and classified according to authorship, manuscript category and research approach/design and subject topic.

\section{- Authorship}

The profession, affiliation and nationality of the first author were considered for authorship classification. For example an author who is a physiotherapist affiliated to a university would be classified academic physiotherapist; while a physiotherapist affiliated to a hospital/ private practice would be classified clinical physiotherapist. Other authors e.g. doctors or nurses were classified 'other'. The abbreviations SA or non-SA were used to indicate whether the first author is South African or not.

\section{- Manuscript Category}

Articles were classified according to the manuscript category used in the SAJ Physiother during the year 2002, which are research articles, case reports, educational reports, scholarly papers and reviews.

\section{- Research approach/design}

Articles were classified into qualitative or quantitative research articles, according to the description by Mouton and Marais (1999). For purposes of this paper, all reviews and scholarly reports were classified in the qualitative category, as they involved no quantification of variables for analytical purposes.

\section{- Topic category}

Three main categories of topics were used namely professional practice aspects, priority research topics and others. The professional aspects summarised the physiotherapists' scope of practice into four broad sub-categories namely research, education, clinical and management.
Priority research topics that were identified were those in line with the National Health Research priorities and included topics on (not exclusive) health behaviour, exercise and the elderly. Topics that did not fall into the above broad categories were classified 'other'.

\section{ASSUMPTIONS AND LIMITATIONS}

This pilot study is limited to articles published in the 2002 volume of the South African Journal of Physiotherapy (SAJ Physiother). The author acknowledges that South African Physiotherapists do publish in other professional journals and/or other countries; and such articles would be excluded from this analysis.

\section{RESULTS AND DISCUSSION}

\section{Authorship and number of articles}

Twenty five (25) articles from the 2002 edition of the SAJ Physiother excluding editorials and letters to the editor were reviewed and analyzed. Tables 1 and 2 indicate a breakdown of the articles according to the previously described content analysis.

- Articles from South African Physiotherapy academics

Academics from 5 out of the 8 physiotherapy institutions published 11 articles in the SAJ Physiother during 2002. Only seven of the eleven articles by academics were research articles as reflected in Table 2.

A finding of concern was the number and distribution of publications amongst the 8 South African universities. Three universities had no publications in the SAJ Physiother in 2002.

The number of articles published by South African Physiotherapy academics $(11 / 25=44 \%)$ in the 2002 volume of the SAJ Physiother is not satisfactory, considering that there are 8 universities in the country training physiotherapists. Research is part of the academics work, and therefore one would expect academics' publications to be in the majority.

In their survey of publication trends in the SAJ Physiother, Dladla et al (1997) found publications by physiotherapy academics for the decade 1984-1994 to be $41 \%$, similar to this pilot study at $44 \%$. However, it must be acknowledged that one year's publication is very limited, and cannot realistically compare to a decade. The SAJ Physiother is a quarterly publication and can only accommodate a limited number of articles per volume.

If these results are confirmed in the bigger study, these issues will need to be seriously addressed so the research

\section{Table 1: Authorship.}

\begin{tabular}{|l|l|l|l|}
\hline Author & SA & Non-SA & Total \\
\hline A cademic -PT & 11 & 4 & 15 \\
\hline Clinical PT & 4 & 4 & 8 \\
\hline O ther & 2 & 0 & 2 \\
\hline TO TA L & 17 & 8 & 25 \\
\hline
\end{tabular}

Table 2: Articles by South African Physiotherapy academics during 2002 (n = 11).

\begin{tabular}{|l|c|c|c|c|c|c|}
\hline \multirow{2}{*}{$\begin{array}{c}\text { Name of } \\
\text { University }\end{array}$} & \multicolumn{5}{|c|}{ Manuscript Category } & Total \\
\cline { 2 - 7 } & Research & Review & Educational & Scholarly & $\begin{array}{c}\text { Case } \\
\text { Report }\end{array}$ & \\
\hline Pretoria & 1 & 1 & 1 & - & - & 3 \\
\hline W its & 1 & 1 & - & 1 & - & 3 \\
\hline Cape Town & 3 & - & - & - & - & 3 \\
\hline Durban W est. & 1 & - & - & - & - & 1 \\
\hline Stellenbosch & 1 & - & - & - & - & 1 \\
\hline Total & 7 & 2 & 1 & 1 & - & 11 \\
\hline
\end{tabular}


agenda for the profession in South Africa can advance, especially in the light of evidence based clinical practice and education! Perhaps this is a challenge that the Education Portfolio of the South African Society of Physiotherapy (SASP) should handle, to make sure education looks after research and is informed by research.

\section{- Articles by clinicians}

The fact that there were more research articles and more publications by South African physiotherapists during 2002 is a positive finding, which should be encouraged. An issue of concern here is the low number of articles by clinicians identified in this pilot study. Clinicians are at the forefront of clinical practice and should ideally be testing out new methods and/or approaches and reporting these in the journal e.g. as case studies.

The attitude of clinicians towards research has been extensively studied in the literature (Connoly et al 2001; Kamwendo 2002). Most clinicians are reportedly keen to conduct and use research in daily work, but cite time and resource constraints amongst factors preventing them from doing so (Hamzat and Amusat 2002). The fact that research is time-consuming a reality that cannot be underplayed; therefore the clinicians concerns should be respected. However, clinicians need to accept the fact that without research knowledge, there can be no evidence for or against clinical effectiveness (Newhorn 1996). Collaboration with academics is one other way of promoting research amongst clinicians, and has been the labeled the 'missing link' between research and practice (Hurley 2000).

\section{Manuscript category}

Sixty percent $(15 / 25)$ of the articles in the sample were research articles. This is a positive finding, given the need for research in physiotherapy. A breakdown of the manuscript category as depicted in table 3 is discussed below.

\section{- Case Reports}

There was only one Case report in the 2002 volume of the SAJ Physiother, suggesting either a lack of awareness on the part of the clinicians regarding this useful approach, or a lack of skills in case report writing or both. Many clinicians would like to contribute to the scientific literature and the case report is an easier and less intimidating method they can use (Hamzat and Amusat 2002). Although putting pen to paper might arouse strong negative feelings of inadequacy, Partridge (2000) argues that writing about your own patients is the best and easiest way to start writing. Papadopoulos (2002) published a very useful guide to Case Reports that the author recommends for those interested in this method.

Case reports are relevant for clinicians as they are in direct contact and communication with patients and can thus give comment on both quantitative and qualitative aspects of outcomes in their reports. Information from case reports can be collected during routine patient care and be written up prospectively or retrospectively. Good records of patient management are crucial in order to write up a case report. As professionals, we need to ensure that our daily encounters with patients are well documented. This is very important for evidence-based practice and the development of the profession. Unless we record what we do and record the results of interventions, we can never prove that we are making a difference. The status of record keeping by South African physiotherapists was found to be not satisfactory by Mkumbuzi et al (2002) in a survey of Physiotherapy records from the Gauteng province.

\section{Research approach/ design}

An inclination towards qualitative research $(13 / 25=52 \%)$ was noted in the pilot study. This may suggest a research

Table 3: Manuscript categories.

\begin{tabular}{|l|l|l|l|}
\hline Category & SA Articles & Non-SA Articles & TOTAL \\
\hline Research & 10 & 5 & 15 \\
\hline Review & 3 & 3 & 6 \\
\hline Scholarly & 2 & 0 & 2 \\
\hline Educational & 1 & 0 & 1 \\
\hline Case Report & 1 & 0 & 1 \\
\hline TO TAL & 17 & 8 & 25 \\
\hline
\end{tabular}

paradigm shift in the profession, in keeping with Durward (2001) who observed that qualitative research has established an important position in the physiotherapy profession.

\section{- Outcomes Research}

Closely linked to the previously mentioned issue of patient records and to EBP is outcomes research (OR), which was found to be lacking in the sample under investigation. There was one scholarly article on outcomes research, and only 2 of the research articles reported on patient outcomes, and focused only on impairment related outcomes with reference to function. We need to measure the impact of our interventions at all three levels of human functioning (i.e. body, person and society) in keeping with the International Classification of Function and disability according to the World Health Organization (WHO 2001).

\section{- Randomized controlled trials (RCT)}

It is also worth noting that there was not a single clinical RCT's in this pilot sample, despite growing international acceptance of the importance thereof. This is in similar to what Duward (2001) found during a 5-year analysis of published research in 'Physiotherapy Research International'. The analysis revealed that the RCT is not the predominant design in Physiotherapy research. This lends support to the views of Durward (2001), who questioned the applicability of the RCT as the golden EBP standard for our profession. Similarly, Bardin (2002) suggests that other research designs should be used in physiotherapy outcomes research as better alternative gold standards, in keeping with the humanistic nature of our profession. 


\section{Subject topic}

- Professional aspects of physiotherapy practice

Sixty percent $(15 / 25)$ of the topics revolved around professional physiotherapy practice. Physiotherapy professional practice involves clinical, teaching, research and management skills that need to be regularly reviewed and refined for best practice through research. The physiotherapy practitioner needs good administrative skills to monitor and manage his/her own practice. A good balance between these aspects of professional practice will result in efficient service rendition to the client (Bitchel 2000).

An interesting finding in this sample is that there were more articles on research $(6 / 25)$ as opposed to other aspects of practice in the profession. Considering the type of research related articles, this is not a cause for concern as most were educational in nature. However, considering the therapeutic nature of our profession, more clinical research is expected.

Another finding of concern is that there were only three education-related articles (i.e. on physiotherapy education) in the sample. Physiotherapy educators are in the business of education and should research education to ensure quality and acceptable standards. One wonders whether this finding is as a result of lack of skills and expertise in educational matters, especially because an educational background or qualifi- -cation is not a prerequisite for teaching physiotherapy in South Africa. Educators need to question whether their teaching methods and approaches are relevant and appropriate or effective. With the recent developments in evidence based medical education, health care educators are expected to base their teaching practice on scientific evidence (Harden 1999).

Physiotherapy education involves teaching and learning by adults. It is important therefore that teaching methods used are appropriate for adults, and are based on the best evidence on the most effective ways of teaching adults (Eksteen 2001). A search of the literature by the author revealed no research on Physiotherapy education to suggest that educators use evidence to select teaching methods or to guide their teaching content. Educational research projects need to be planned and implemented with the aim of measuring the effectiveness of a specific strategy (Harden et al 1999)). Educational strategies and techniques should be implemented on the basis of evidence, not just because they are in fashion (Eksteen 2001).

\section{- Priority research issues}

The importance of physiotherapy in health promotion is becoming realized as is evident in three articles on health behavior. This is in line with the national health plan (Department of Health 2001) and it is essential that physiotherapy is not left behind. We need to be seen to be a relevant and essential service in the

Table 4: Topic categories.

\begin{tabular}{|l|c|}
\hline \multicolumn{1}{|c|}{ Topic Category } & Number \\
\hline Professional A spects of Practise & 3 \\
Educational practice & 5 \\
Clinical Practice (+ techniques) & 6 \\
Research practice & 1 \\
Management practice & \\
\hline Priority Research Issues & 3 \\
Health Behaviour studies & 4 \\
Exercise & 1 \\
The elderly & 1 \\
\hline O ther topics & 1 \\
Human Resources & $\mathbf{2 5}$ \\
\hline Pharmacology & \\
\hline TO TAL & \\
\hline
\end{tabular}

health system and outcome studies in the health promotion area are one way of proving our worth.

It is quite concerning that there were no articles on HIV/AIDS, children, women's health and disability in the 2002 volume of the SAJ Physiother. These are not only physiotherapy research priorities, but national priorities as far as health care research is concerned (Department of Health 2001). One can only hope that this finding is only due to the small sample piloted. It is also acknowledged that physiotherapists are likely to publish on the outcome of physiotherapy in this journal, but may rather publish other health-related topics e.g. HIV/AIDS, geriatrics etc in more relevant journals.

\section{- Other topics}

There were two 'other' topics in the sample namely pharmacology and human resources, which are emerging fields important to Physiotherapy. Pharmacology is a new aspect of physiotherapy practice, which was introduced with the possibility that physiotherapists may legally be allowed to prescribe medications in the future.

Issues of human resources (i.e. staffing) are important to physiotherapy. It is important for the profession to collect scientific data on such issues, so that when the need to convince the 'powers that be' we are well armed to motivate (e.g. for more posts) with the necessary evidence (De Charmoy and Eales 2000).

\section{IMPLICATIONS FOR PHYSIOTHERAPY GOVERNANCE STRUCTURES}

In the light of this pilot study findings and the deductions arrived at, there is a need for a research management system for the Physiotherapy profession. The system I propose revolves around three major stakeholders (and is depicted in figure 1).

- The South African Society of Physiotherapy (SASP) - to offer research support and guidance to members;

- The Physiotherapists themselves - to actively conduct and use research in their professional practice

- The Professional board for Physiotherapy, Podiatry and Biokinetics - 
the quality assurer to monitor professional research

1. The South African Society of Physiotherapy (SASP)

The Physiotherapy Research Foundation (PRF)

The SASP has structures and mechanisms in place to improve clinical skills through the special interest groups. There is however, not much in place to promote research development in the profession, except for the incentive of a grant from the Physiotherapy Research Foundation (PRF) for physiotherapists involved in research. The PRF is a trust of the SASP established in 1996, with the main objective of promoting research within the profession (SASP Brochure - 1996). PRF Grant recipients have to date been post graduate students and academics (Fearnhead 2003). These are unfortunately people that have to do research anyway, PRF grant or no grant. To them the PRF becomes 'an enabling means to an end' they have to achieve. The SASP needs to find creative ways of enticing practicing physiotherapists to get involved in research, for the sake of the profession.
The author proposes that the SASP should investigate the possibility of a research division within the society. A suggestion is for the scope of the education portfolio of the SASP to be broadened to include research as a professional development issue, and not focus only on educational issues. Professional research has no special interest group and is just left to interested individuals. This research division can be a department within the education portfolio - whose mandate will only be professional research development, looking at the PRF, the Propagation of

Figure 1. Proposed Framework for Improving Physiotherapy Research in South Africa.

\begin{tabular}{|c|c|c|}
\hline $\begin{array}{c}\text { THE SASP } \\
=\text { RESEARCH SUPPO RT }\end{array}$ & $\begin{aligned} & \text { PHYSIO THERAPISTS } \\
= & \text { RESEARCH ACTIVITY }\end{aligned}$ & $\begin{array}{l}\text { PRO FESSIO NAL BOARD } \\
=\text { QUAUTY ASSURANCE }\end{array}$ \\
\hline $\begin{array}{l}\text { Research Division to promote } \\
\text { research development through: } \\
\text { - Develop capacity } \\
\text { W orkshops and courses } \\
\text { on EBP, Research } \\
\text { and publication skills } \\
\text { Foundation and the Propagation } \\
\text { of Professional Knowledge } \\
\text { (PPK) Fund } \\
\text { - To incentivise members } \\
\text { to engage in } \\
\text { professionally } \\
\text { meaningful research } \\
\text { committee of the education } \\
\text { Portfolio during Congress } \\
\text { preparations } \\
\text { - Ensure Research } \\
\text { standards } \\
\text { presenters during } \\
\text { abstract review }\end{array}$ & $\begin{array}{l}\text { Start working on } \\
\text { A Attending Researc } \\
\text { courses/ workshops } \\
\text { - Improved } \\
\text { documentation of } \\
\text { patient records } \\
\text { - Submitting case } \\
\text { reports of } \\
\text { interventions and/ or } \\
\text { outcomes for } \\
\text { Publication } \\
\text { - Presenting at } \\
\text { scientific gatherings } \\
\text { research projects in } \\
\text { collaboration with } \\
\text { others }\end{array}$ & $\begin{array}{l}\text { Monitors Research in the } \\
\text { Profession through CPD. } \\
\text { - Mandatory Research } \\
\text { related CPD Points } \\
\text { - More points } \\
\text { obtainable through } \\
\text { Research related } \\
\text { activities }\end{array}$ \\
\hline
\end{tabular}


Professional Knowledge (PPK) fund and other capacity building activities. This may well be what is needed to push the national research agenda forward, and it seems to have worked well for other associations. Developed associations like the Chartered Society of Physiotherapy have established Research offices and functional Research strategies (CSP Research Strategy 1995).

\section{Professional Board}

The Health Professions Council of South Africa (HPCSA) introduced a point reward system for continuing professional development (CPD) for physiotherapists, on trial in 2002 and mandatory from 2003 (Eales 2000). The author views this as a mechanism to foster professional development, which might enforce research in the profession.

The newly introduced Continuous Professional Development (CPD) Point system is a potential research incentive because more CPD points can be obtained through research related activities (e.g. completion of postgraduate studies). Research is the first and basic step to evidence based practice (Bitchel 2000), and a possible enforcement would be for the board to dictate that a certain percentage of the 30 points per annum must be obtained through research related activities such as it is specified for ethics and cardiopulmonary resuscitation (Eales 2000). In this way, the profession would be guaranteed that all physiotherapists engage in some form of research activity every year.

\section{The physiotherapists}

Physiotherapists need to engage in research activities for their own development and to contribute to the professional body of knowledge. The author recommends the following 'Research start-up' suggestion from Grant (1997) especially for those physiotherapists with the 'fear of research':

- Keeping a good record of patients' treatments and outcomes. National data on types of patients attending physiotherapy, types of treatment given, number of treatments and results are lacking in every country. Your records can help to address this deficit.
- Starting, or joining a journal club in your physiotherapy department, or school or geographical area. Reading and discussion with others, discussion with others and critical evaluation of published papers is important.

- Sharing patient problems/successes with others or submitting case studies to your newsletter. Remember that observation and contemplation were the hallmarks of those clinicians who have made the greatest contributions to the development of our knowledge base for physiotherapy practice.

- Joining others in a team to undertake research. Establish close links with your department of physiotherapy or professional association so that collaborative research might be undertaken.

- Undertaking formal research. This is vital to our profession, as this will provide leadership in clinical research and in evidence-based practice.

- Contributing to physiotherapy research financially, or in other ways. Even small financial contributions can be invaluable when added with others. Consider making your records, or patients available for clinical research; consider offering to be a co-supervisor or assistant supervisor of a student undertaking a research project. Always respond positively to invitations to participate in research (e.g. reply to research questionnaires).

\section{CONCLUSSION}

This study reflects on the results of a pilot study designed to test the feasibility of a content analysis methodology. The content analysis methodology was found to be appropriate for describing the content of the journal under review, and also for analyzing the articles in order to reflect on the research questions posed. The only limitation was the small sample size from one year. This method is therefore recommended and will be carried forth in the bigger study with a larger sample of articles. Although the pilot findings cannot be generalized to physiotherapy research in South Africa, they do highlight important issues regarding research and professional practice.

Because this paper reflected on findings from a pilot study, one cannot realistically answer the questions posed in the introduction at this stage. The pilot study findings however do suggest that the articles in the 2002 volume of the SASP Journal do display some relevancy towards the country's health needs more than towards evidencebased practice. We need to reflect on this and ask ourselves the question: 'is our research relevant?' A model for promoting physiotherapy research in South Africa is thus proposed (figure 1).

\section{REFERENCES}

Bardin LD (2002): Physiotherapy and low back pain - Part 1: Outcomes Research in the Quest for evidence. SA Journal of Physiotherapy 58 (3): 3-7

Bitchell C (2000): Evidence-based Physiotherapy. Some thoughts on 'best Evidence'. Physiotherapy 86 (2):58-60

Chartered Society of Physiotherapy (1995): CSP Research strategy. Physiotherapy 81 (5) 285-289

Connoly BH, Lipinnaci NS, Bush AJ (2001): Changes in attitude and perception about research in physical therapy among professional physical therapist students and new graduates. Phys Thyer 81: 1127 - 1134

Currier DP (1990) Qualitative Research. Elements of research in Physical Therapy. 3rd ed. Baltimoer,MD:Williams and Wilkins co.

Dahlgren MA (1999): Editorial. Advances in Physiotherapy 1: 1 - 2

De CharmoyS Eales CJ (2000) An audit of the physiotherapy services at the Johannesburg hospital. SA Journal of Physiotherapy 56(1) 21-23

Department of Health (2001): Draft National Health Bill. Chapter 9: Health Surveillance, Research and information. Available at www.doh.gov.za/docs/bills/nhb.htm

Durward B (2001) Editorial - Progress by design. Physiotherapy Research International 6 (2) iii - iv

Eales CJ (2000): Editorial - Change: 'Make or become different' or simply making a difference. Physiotherapy Research International 5(2) 3 - 4

Eales CJ (2000) Life long learning and continuing professional development. A paper presented at the SASP Mini-congress in Rustenburg, South Africa. 
Eksteen CE (2001): Challenges facing Physiotherapy Education. SA Journal of Physiotherapy 57(4):2 - 3

Fearnhead L (2003): The Physiotherapy Research Foundation of the SASP. Information discussed during the Policy Committee meeting of the SASP.

Grant R (1998): Dimensions of excellence "Second curve thinking" and progress in Physiotherapy SA Journal of Physiotherapy 54(4) 4 - 10

Gulham E (2000): Editorial - Evidence-Based practice and professional credibility. Physiotherapy Theory and Practice 14: $65-67$

Harden RM, Grant J, Graham B \& Hart IR (1999): BEME Guide no.1: Best evidence medical education. Medical Teacher 8(6): $111-124$

Hamzat TK, Amusat NT (2002): Belief and participation of clinical physiotherapists in research SA Journal of Physiotherapy 58 (2): $32-34$
Hurley M (2000): Linking research with practice: The missing link - Collaboration. Physiotherapy 86 (70 339 - 341

Jette AM (1995): Outcomes research - shifting the dominant research paradigm in Physical Therapy. Physical Therapy 75: 965 - 970

Kamuendo K (2002): What do Swedish physiotherapists feel about research? A survey of perceptions, attitudes, intentions and engagement. Physiotherapy Research International 7(1) 23 - 34

Klopper HC (2002): A constructivist strategy for Health Science education. SA Journal of Physiotherapy 58(4):13 -183

M'kumbuzi VRP, Eales CJ, Stewart A (2002): An analysis of the completion of physiotherapy clinical records in the Gauteng province. SA Journal of Physiotherapy 58 (1): 18 - 27

Mouton J, Marais HC (1994): Basic concepts in the methodology of the social sciences. HSRC Publishers, Pretoria pp 144-151
Newhorn D (1996): Physiotherapy - lip service or commitment (Editorial). Physiotherapy Theory and Practice 12: 1-2

Papadopoulos M (2002) Basic guidelines for preparing a case report. SA Journal of Physiotherapy 58(3): 33 - 36

Patridge CJ (2000) Editorial - Case reports in Physiotherapy. Physiotherapy Research International 5: iv - v

Ritchie J.E (1999): Using qualitative research to enhance the evidence-based practice of health care providers. Australian Journal of Physiotherapy 45:251 - 256

South African Society of Physiotherapy (1996): Compton brochure - Physiotherapy Research Foundation.

World Health Organization (2001): International Classification of Functioning, disability and health. Available at www.who.int/icf/icftemplate.cfm

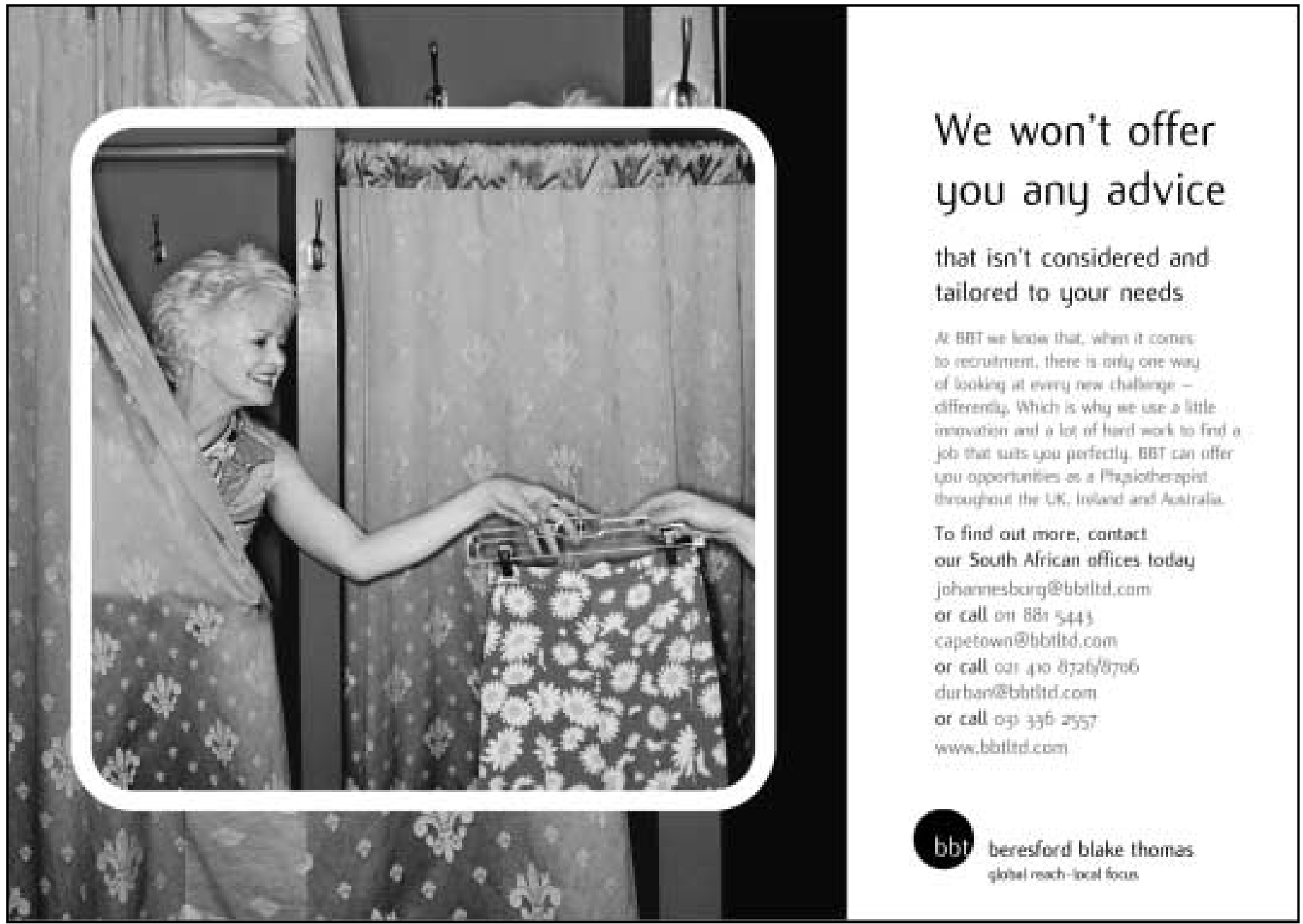

